$$
\begin{aligned}
& \text { ANL/CHM/CP- }-88667 \\
& \text { C.ONF }-960772--20
\end{aligned}
$$

\title{
THE THERMAL DECOMPOSITION OF C2H5I
}

$$
\text { by }
$$

\author{
S. S. Kumaran, M.-C. Su, $\ddagger$ K. P. Lim, and J. V. Michael ${ }^{*}$ \\ Chemistry Division, Argonne National Laboratory, Argonne, IL 60439, USA \\ Corresponding Author: Dr. J. V. Michael \\ D-193, Bldg 200 \\ Argonne National Laboratory \\ Argonne, IL 60439 \\ Phone: (708) 252-3171, Fax: (708) 252-4470 \\ E-mail: Michael@ANLCHM.BITNET
}

(26th Symp. (Int'l) on Combust., Submitted Dec., 1995)

Desired Presentation: Oral

Preferred Publication: Proceedings

Category: React. Kinetics Code Numbers: $\quad$ 1.1, 1.5

\begin{tabular}{|c|c|c|c|c|c|}
\hline & Text & Reference & Tables & Figures & Total \\
\hline Count & 3037 words & 37 citations & 4 pages & 5 pages & \\
\hline & & & & & \\
Equiv. Words & 3037 & 747 & 800 & 1000 & 5584 \\
\hline
\end{tabular}

(NOT PATENTABLE)

The submitted manuscript has been authored by a contractor of the U.S. Government under contract No. W-31-109-ENG-38. Accordingly, the U.S. Government retains a nonexclusive, royalry-free license to publish or reproduce the published form of this contribution, or allow others to do so, for U.S. Government purposes.

¥Sabbatical Leave. Permanent address: Department of Chemistry, Butler University, Indianapolis, IN 46208.

This work was supported by the U. S. Department of Energy, Office of Basic Energy Sciences, Division of Chemical Sciences, under Contract No. W-31-109-Eng-38. 


\section{DISCLAIMER}

Portions of this document may be illegible in electronic image products. Images are produced from the best available original document. 


\begin{abstract}
The high temperature thermal dissociation of $\mathrm{C}_{2} \mathrm{H}_{5} \mathrm{I}$ has been characterized in this study. Kinetics and overall yield experiments were performed over the temperature range, 946-2046 K, using the atomic resonance absorption spectrometric technique (ARAS) for the temporal detection of both product $\mathrm{H}$ - and I-atoms behind reflected shock waves. The $\mathrm{C}_{2} \mathrm{H}_{5} \mathrm{I}$ decomposition proceeds by both $\mathrm{C}-\mathrm{I}$ fission and $\mathrm{HI}$ elimination. Rate constants for the C-I fission process, measured over the temperature and density ranges, 946-1303 K and $0.82-4.4 \times 10^{18} \mathrm{~cm}^{-3}$, respectively, can be well represented to within $\pm 37 \%$ by the first-order expression: $\mathrm{k}=6.34 \times 10^{9} \exp (-15894 \mathrm{~K} / \mathrm{T}) \mathrm{s}^{-1}$. Overall yield data for atomic product gave a branching ratio for $\mathrm{C}-\mathrm{I}$ fission of $(0.87 \pm 0.11)$ suggesting that $13 \%$ of the reaction proceeds through molecular $\mathrm{HI}$ elimination. This conclusion is consistent with earlier studies that showed C-I fission to be the dominant dissociation channel.

The temperature and pressure dependences of the dissociation rate constants and the yield data have been theoretically described using three formulations of unimolecular rate theory. The best description was obtained with a full Master's equation analysis. However, all three calculations confirm that the HI elimination pathway is lower lying than the C-I fission process by $\sim 3 \mathrm{kcal} \mathrm{mole}^{-1}$.
\end{abstract}

\title{
DISCLAIMER
}

\footnotetext{
This report was prepared as an account of work sponsored by an agency of the United States Government. Neither the United States Government nor any agency thereof, nor any of their employees, makes any warranty, express or implied, or assumes any legal liability or responsibility for the accuracy, completeness, or usefulness of any information, apparatus, product, or process disclosed, or represents that its use would not infringe privately owned rights. Reference herein to any specific commercial product, process, or service by trade name, trademark, manufacturer, or otherwise does not necessarily constitute or imply its endorsement, recommendation, or favoring by the United States Government or any agency thereof. The views and opinions of authors expressed herein do not necessarily state or reflect those of the United States Government or any agency thereof.
} 


\section{Introduction}

Thermal chemical reactions often involve multiple reaction pathways. In both unimolecular and bimolecular reactions, the extent of branching into different product channels depends on the nature of the intermediate configurations and the thermochemistry. In unimolecular reactions, this is determined by the reaction thresholds and transition state properties for the respective pathways. There are not many reaction systems that delineate these features even though it has been suggested that understanding the kinetics in pyrolysis and combustion systems requires such detailed descriptions. [1] Before the development of unimolecular rate theory can continue to proceed, some unambiguous experimental observations on multi-channel dissociations are required. The effects of such quantities as the collisional energy transfer parameter and the fall-off behavior (as functions of both temperature and density) on the branching ratios would be particularly informative. Theoretical characterization would then be essential for a predictive application to unstudied systems. This of course is a strong need, for example, in the development of detailed kinetics in combustion systems. [1]

Recent experiments on $\mathrm{CH}_{2} \mathrm{Cl}_{2}$ [2] and $\mathrm{COCl}_{2}$ [3] from this laboratory have shown these to be typical two-channel unimolecular dissociations involving both $\mathrm{C}-\mathrm{Cl}$ bond fission and molecular elimination ( $\mathrm{HCl}$ or $\mathrm{Cl}_{2}$, respectively). In this paper, the thermal decomposition kinetics of $\mathrm{C}_{2} \mathrm{H}_{5} \mathrm{I}$ are studied using both $\mathrm{H}$ - and I-atom atomic resonance absorption spectrometric (ARAS) techniques. From thermodynamic considerations, the pathways available for thermal dissociation are C-I fission and molecular $\mathrm{HI}$ elimination. This should be contrasted with the other haloethanes, $\mathrm{C}_{2} \mathrm{H}_{5} \mathrm{~F}$, $\mathrm{C}_{2} \mathrm{H}_{5} \mathrm{Cl}$, and $\mathrm{C}_{2} \mathrm{H}_{5} \mathrm{Br}$, where $\mathrm{HX}$ elimination requires $\sim 50 \mathrm{kcal}$ mole-1 whereas bond fission requires a much larger energy effectively eliminating $\mathrm{C}-\mathrm{X}$ bond fission as a viable dissociation channel. In $\mathrm{C}_{2} \mathrm{H}_{5} \mathrm{I}$, the $\mathrm{C}-\mathrm{I}$ bond fission channel,

$$
\mathrm{C}_{2} \mathrm{H}_{5} \mathrm{I}(+\mathrm{M}) \rightarrow \mathrm{C}_{2} \mathrm{H}_{5}+\mathrm{I}(+\mathrm{M})
$$


yields $\mathrm{C}_{2} \mathrm{H}_{5}$ which will undergo fast subsequent decomposition,

$$
\mathrm{C}_{2} \mathrm{H}_{5}(+\mathrm{M}) \rightarrow \mathrm{C}_{2} \mathrm{H}_{4}+\mathrm{H}(+\mathrm{M})
$$

since $\Delta H_{0(1 a)}^{0}=34.8 \mathrm{kcal} \mathrm{mole}^{-1}$ is much lower than $\Delta H_{0(1)}^{0}$. The overall process is then $\mathrm{C}_{2} \mathrm{H}_{5} \mathrm{I}=\mathrm{C}_{2} \mathrm{H}_{4}+\mathrm{H}+\mathrm{I} . \mathrm{C}_{2} \mathrm{H}_{5} \mathrm{I}$ has in fact been used as a source of $\mathrm{H}$-atoms for gas phase kinetics studies. [4,5]

The molecular elimination channel,

$$
\mathrm{C}_{2} \mathrm{H}_{5} \mathrm{I}(+\mathrm{M}) \rightarrow \mathrm{C}_{2} \mathrm{H}_{4}+\mathrm{HI}(+\mathrm{M})
$$

has been theoretically [6,7] shown to involve a 4-center transition state in contrast to the 3center processes in $\mathrm{CH}_{2} \mathrm{Cl}_{2}$ and $\mathrm{COCl}_{2}$. Both Herzler and Frank [4] and Mertens et al. [5] have assumed that reaction (2) was negligible. However, using the most recent value [8] for $\Delta_{f} H_{298 K\left(C_{2} H_{5} I\right)}^{0}=-1.72 \mathrm{kcal} \mathrm{mole}^{-1}$ combined with the JANAF [9] recommendations for $\mathrm{C}_{2} \mathrm{H}_{4}$ and $\mathrm{HI}$ gives $\Delta H_{298 K(2)}^{0}=20.6 \mathrm{kcal} \mathrm{mole}-1$. With $\Delta_{f} H_{298 K\left(C_{2} H_{5}\right)}^{0}=28.7 \mathrm{kcal}$ mole-1 from Hanning-Lee et al., [10] $\Delta H_{298 K(1)}^{0} \cong 56 \mathrm{kcal} \mathrm{mole}^{-1}$; i. e., $\sim 35 \mathrm{kcal} \mathrm{mole}^{-1}$ higher. The reverse 4-center process, $\mathrm{HI}$ addition to $\mathrm{C}_{2} \mathrm{H}_{4}$, has an estimated $[6,11]$ insertion barrier of $\sim 30 \mathrm{kcal} \mathrm{mole}^{-1}$, suggesting that the threshold energies for reactions (1) and (2) could be nearly isoenergetic.

There are earlier studies that have attempted to characterize the decomposition. $\mathrm{R}$. A. Ogg, Jr. [12] studied the thermal system, $\mathrm{HI}$ with $\mathrm{C}_{2} \mathrm{H}_{5} \mathrm{I}$, over small temperature (523$573 \mathrm{~K}$ ) and pressure (145-177 Torr) ranges. Using calorimetric determination of [] and with an assumed reaction mechanism, $k_{1}=1.82 \times 10^{13} \exp (-21638 \mathrm{~K} / \mathrm{T}) \mathrm{s}^{-1}$; i. e. reaction (1) was rationalized as being first-order. Reaction (2) was not even considered in this analysis. Sullivan [13] later reinterpreted the results of Ogg [12] and estimated $k_{1}=1.54 \mathrm{x}$ $10^{16} \exp (-26167 \mathrm{~K} / \mathrm{T}) \mathrm{s}^{-1}$. He further suggested that the $\mathrm{C}-\mathrm{I}$ bond strength in $\mathrm{C}_{2} \mathrm{H}_{5} \mathrm{I}$ was 
$52.0 \mathrm{kcal} \mathrm{mole}^{-1}$. Butler and Polanyi [14] were the first to postulate that both channels (1) and (2) could be thermally accessible in the dissociation of $\mathrm{C}_{2} \mathrm{H}_{5} \mathrm{I}$. Yang and Conway [15] then studied the $\mathrm{C}_{2} \mathrm{H}_{5} \mathrm{I}$ pyrolysis at higher temperatures (660-794 $\mathrm{K}$ ) using the toluenecarrier flow technique. They measured the rate constant for reaction (2) and concluded that it was first-order over the toluene pressure range, 2-18 Torr, and $\mathrm{C}_{2} \mathrm{H}_{5} \mathrm{I}$ pressure range, $(0.6-40) \times 10^{-3}$ Torr. They [15] reported $k_{2}=1.27 \times 10^{14} \exp (-26569 \mathrm{~K} / \mathrm{T})$ at 14 Torr

total pressure. From the extrapolated value, $k_{1}=4.50 \times 10^{13} \exp (-25160 \mathrm{~K} / \mathrm{T})$, this work suggested that $\sim 70 \%$ of the reaction occurs through reaction (1). It is clear that these earlier studies have not fully explored the $\mathrm{C}_{2} \mathrm{H}_{5} \mathrm{I}$ pyrolysis; i. e., the temperature and density dependences of the rate constants for (1) and (2).

A thorough study of the $\mathrm{C}_{2} \mathrm{H}_{5} \mathrm{I}$ decomposition requires kinetics measurements under chemical isolation conditions in order to unambiguously determine reaction rates and yields. The ARAS method combined with shock tube equipment is well suited for this purpose. The thermal dissociation of $\mathrm{C}_{2} \mathrm{H}_{5} \mathrm{I}$ was studied by observing the temporal formation of both $\mathrm{H}$ - and I-atoms behind reflected shock waves. The calibration for $\mathrm{H}$ and I-atom ARAS detection techniques are completely independent and are detailed below. Because of the difference in the $\mathrm{H}$-atom and I-atom ARAS detection sensitivities, separate set of experiments were carried out. However, these experiments were performed over nearly the same temperature ranges, $1080-2020 \mathrm{~K}$ (H-atom) and 946-2046 K (I-atom).

\section{Experimental}

The shock tube ARAS experiments were performed behind reflected shock waves. The experimental approach used here is similar to that described elsewhere. $[16,17]$ Experiments were performed under highly dilute conditions so as to minimize secondary chemistry and thereby obtain chemical isolation.

Apparatus: The shock tube used here has already been described. [16] The $7 \mathrm{~m}$ circular tube (i.d. $9.74 \mathrm{~cm}$ ) was separated from the driver by a thin aluminum diaphragm (4 mil unscored $1100-\mathrm{H} 18$ ). The tube was routinely pumped to $<10^{-8}$ Torr between experiments 
by a packaged pump system (Edwards Vacuum Products, model CR100P). Shock waves were produced by manually breaking the diaphragm at a known driver pressure of highpurity He. Boundary layer corrected post reflected shock properties were calculated from incident shock wave velocities that were measured by eight equally spaced pressure transducers (PCB Piezotronics, Inc., model 113A2) located well down stream from the diaphragm. [18-20] Both pressure and absorption data were recorded using a Nicolet 4094C digital storage oscilloscope.

H-atom ARAS Detection: The ARAS technique was used to measure $[\mathrm{H}]_{t}$. [21] The $\mathrm{H}-$ lamp was operated under a 2 Torr flow-pressure of UHP He with the microwave discharge power set to $40 \mathrm{~W} . \mathrm{H}_{2}$ and $\mathrm{CH}_{4}$ impurities present in the He gave sufficient $\mathrm{Ly} \alpha$ signal through an $\mathrm{O}_{2}$ (1 atm of dry air) gas filter. A discharge flow system containing highpurity $\mathrm{H}_{2}$ in the optical path provided an atomic filter that was used to establish the fraction of non-Ly $\alpha$ light. Line reversal was negligible under these conditions. The observed data were the time dependent transmittances, and from these, $[\mathrm{H}]_{t}$ profiles were obtained from routine $\mathrm{Ly} \alpha$ line absorption calculations using the known absorption oscillator strength for a Doppler-broadened source at an equivalent lamp temperature of $480 \mathrm{~K} .[22,23]$ The $\mathrm{Ly} \alpha$ oscillator strength is a priori better known than those for any other spectral transition. Absolute $[\mathrm{H}]$ determination with this ARAS detection method in reflected shock waves has already been experimentally validated. $[21,24]$

I-atom ARAS Detection: The ARAS technique for I-atom detection has been recently described. [25] The I-atom resonance lamp configuration (2 Torr flow of $0.1 \% \mathrm{CF}_{3} \mathrm{I}$ in UHP He, at $50 \mathrm{~W}$ microwave power) is similar to the $\mathrm{Cl}$-atom lamp detailed elsewhere. ${ }^{24}$ Lamp emission was observed with a solar blind EMR G14 PMT (quantum efficiency, 3\%) through a suprasil filter over a wavelength range of $165-185 \mathrm{~nm}$ without further spectral resolution. The absorption spectrum of I-atoms in this region corresponds to the transitions, ${ }^{2} P_{3 / 2}$ and ${ }^{4} P_{5 / 2,1 / 2} \leftarrow{ }^{2} P_{3 / 2}^{0}$ (principally $\lambda=183.0 \mathrm{~nm}$ ). [26] A purge of dry $\mathrm{N}_{2}$ between the PMT and the shock tube window eliminated $\mathrm{O}_{2}$ from the beam path. 
I-atom calibration using $\mathrm{CF}_{3} \mathrm{I}$ as the thermal source of [I] has been described. [25] In that study, varying $\mathrm{CF}_{3} \mathrm{I}-\mathrm{Kr}$ mixtures were shock heated at sufficiently high temperatures to completely dissociate $\mathrm{CF}_{3} \mathrm{I}$. The long time transmittance values correspond unambiguously to an I-atom concentration, []$_{\infty}$, equal to $\left[\mathrm{CF}_{3} \Pi_{0}\right.$. However, construction of an absorbance, $(\mathrm{ABS})_{\infty} \equiv-\ln \left(I_{\infty} / I_{0}\right)$, against []$_{\infty}$ relationship (the curveof-growth) requires a prior knowledge of the fraction of light that is non-resonant. This fraction was determined to be $(0.49 \pm 0.02)$. [25] Long-time absorbance values, $(A B S)_{\infty}$, corresponding to []$_{\infty}=\left[\mathrm{CF}_{3}\right]_{0}$, were calculated from the known non-resonant fraction of light, and the curve-of-growth was constructed. The curve-of-growth is linear for $\Pi \leq 3 \mathrm{x}$ $10^{12} \mathrm{~cm}^{-3}$ being best represented by the linear Beer's law expression,

$$
(\mathrm{ABS})=1.9215 \times 10^{-13} \text { 四 }
$$

where $[M]$ is given in molecules $\mathrm{cm}^{-3}$. The I-atom absorption cross-section is $\sigma=1.933 \mathrm{x}$ $10^{-14} \mathrm{~cm}^{2}$, and this is in good agreement with earlier determinations. [27,28] At higher concentrations the curve becomes increasingly non-linear.

Gases: High-purity He (99.995\%) from Air Products and Chemicals was used as the driver gas. $\mathrm{Kr}$ (Scientific Grade, 99.997\%) used as the diluent in the experimental mixtures was obtained from MG Industries. UHP Grade He (99.995\%) from Airco was used as the diluent in the I-atom lamp mixture and for the H-atom resonance lamp. Also obtained from Airco was the high-purity $\mathrm{H}_{2}$ (99.995\%) for the atomic filter. $\mathrm{CF}_{3} \mathrm{I}$ (99\%) for the I-atom resonance lamp and $\mathrm{C}_{2} \mathrm{H}_{5} \mathrm{I}$ (99\%) were obtained from Aldrich Chemical Co. Inc. Reactant $\mathrm{C}_{2} \mathrm{H}_{5} \mathrm{I}(99 \%)$ was further purified by bulb-to-bulb distillation with the middle third being retained for mixture preparation. All gas mixtures were stored in a glass vacuum line, and an MKS Baratron capacitance manometer was used for pressure measurements. 


\section{Results}

In this study, two sets of shock tube ARAS experiments were carried out, and rate constants and yields were measured for both. Because reaction (1a) is much faster than (1) and secondary reactions are negligible at the $\left[\mathrm{C}_{2} \mathrm{H}_{5} \mathrm{I}\right]_{0}$ used, all observed $[\mathrm{H}]$ or $[\mathrm{I}$ is a result of reaction $(1)$; i. e., $[\mathrm{H}]_{\infty}$ or []$_{\infty}$ should unambiguously correspond to the yield from the C-I fission channel. This is confirmed by iterative kinetics calculations using the mechanism in Table I. Note that $\mathrm{H}$-atom abstraction of either $\mathrm{H}$ or $\mathrm{I}$ from $\mathrm{C}_{2} \mathrm{H}_{5} \mathrm{I}$ is not included in the mechanism because these rate constants are negligible and do not contribute to either $[\mathrm{H}]_{\mathrm{t}}$ or $\left[\mathrm{I}_{\mathrm{t}}\right.$ with the present dilute conditions. [30]

$38 \mathrm{H}$-atom ARAS experiments at $\mathrm{T}>1220 \mathrm{~K}$ were used to determine $[\mathrm{H}]$ yields. From the transmittance value $T_{\infty} \equiv\left(I_{\infty} / I_{0}\right)$ (and corresponding absorbance value, (ABS) $\left.\equiv-\ln \left(T_{\infty}\right)\right),[\mathrm{H}]_{\infty}$ was obtained through line absorption calculations [21-24] at the temperature of a given experiment. With the Table 1 mechanism, observed $[\mathrm{H}]_{\infty}$ can be recovered by using a branching ratio, $\mathrm{k}_{1} /\left(\mathrm{k}_{1}+\mathrm{k}_{2}\right)$, that is identical to the observed yield defined as $[\mathrm{H}]_{\infty} /\left[\mathrm{C}_{2} \mathrm{H}_{5} \mathrm{I}\right]_{0}$, showing that reaction (3) in Table $\mathrm{I}$ is negligible. The H-atom yield values are plotted in Fig. 1 as solid circles which give the least-squares average, $[\mathrm{H}]_{\infty} /\left[\mathrm{C}_{2} \mathrm{H}_{5} \mathrm{I}\right]_{0}=(0.85 \pm 0.07)$, implying $\mathrm{k}_{2} / \mathrm{k}_{1}=0.18$. It is obvious that the molecular elimination channel, reaction (2), does have significance. Similar experiments were

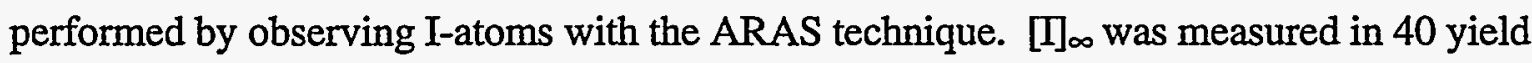
experiments over the temperature range 950-2050 $\mathrm{K}$ with the ARAS technique. [25] These experiments differ from the H-atom experiments in two ways: (i) the I-atom product from reaction (1) is directly observed and does not depend on the occurrence of reaction (1a), and; (ii) the [I] detection range (i. e., (1-8) x $10^{12}$ molecule $\mathrm{cm}^{-3}$ ) is $\sim 10$ times higher than that for $[\mathrm{H}]$. The yield results are also displayed in Fig. 1 as open circles. This set gives $\Pi]_{\infty} /\left[\mathrm{C}_{2} \mathrm{H}_{5} \Pi_{0}=(0.89 \pm 0.07)\right.$, implying $\mathrm{k}_{2} / \mathrm{k}_{1}=0.12$, in agreement with the $\mathrm{H}$-atom results. If the two sets are combined, the $\mathrm{T}$-independent value, $(0.87 \pm 0.11)$ is obtained giving $\mathrm{k}_{2} / \mathrm{k}_{1} \cong 0.15$. 
Four $\mathrm{H}$-atom rate constant measurements were made at $\mathrm{T}<1230 \mathrm{~K}$ where the temporal formation of $\mathrm{H}$-atoms was fully time resolved. The top panel of Fig. 2 shows a typical experimental record, and these transmittance data were converted to $[\mathrm{H}]_{t}$ giving the bottom panel. With a fixed $\mathrm{k}_{2} / \mathrm{k}_{1}$ set by $[\mathrm{H}]_{\infty}, \mathrm{k}_{1}$ was adjusted to best fit the $[\mathrm{H}]_{t}$ profile using the full Table 1 mechanism. This is illustrated in Fig. 2 (bottom panel) where the best fit to $[\mathrm{H}]_{t}$ is shown as the line. Derived first-order rate constants for reaction (1) are given in Table 2 along with the corresponding second-order values. More extensive rate constant measurements were made with the I-atom ARAS detection method. A typical record is shown in Fig. 3. Using eqn. (3), transmittance data were converted to []$_{t}$ giving the profile displayed in the bottom panel. As before, $[\Pi]_{t}$ was fitted with the Table 1 mechanism by adjusting $\mathrm{k}_{1}$ and the ratio, $\mathrm{k}_{2} / \mathrm{k}_{1}$. Even with somewhat higher $\left[\mathrm{C}_{2} \mathrm{H}_{5}\right]_{0}$, the [I] values are still not perturbed by abstraction (reaction (3) in Table 1). The solid line in the bottom panel of Fig. 3 illustrates the quality of fits used for deriving the first- and second-order rate constants listed in Table 2.

The results in Table 2 are plotted in Fig. 4 as first-order rate constants simply because we anticipate that this decomposition may be in the fall-off region. The linear least squares line shown in the figure is given by,

$$
\mathrm{k}_{1}=6.34 \times 10^{9} \exp (-15894 \mathrm{~K} / \mathrm{T}) \mathrm{s}^{-1}
$$

for the T-range, $946-1303 \mathrm{~K}$. The points shown in the figure are within $\pm 37 \%$ of the line at the one standard deviation level.

\section{Discussion}

Since the threshold energies reactions (1) and (2) are within a few kcal mole-1 of one another, the $\mathrm{C}_{2} \mathrm{H}_{5} \mathrm{I}$ decomposition might be a nearly degenerate two channel reaction system. Yang and Conway [15] showed that (2) is not negligible. However, the 
subsequent experiments at higher temperature substantiate that (1) must dominate. $[4,5]$ These conclusions are corroborated in the present work.

In order to fully characterize this decomposition, we have performed three types of unimolecular rate theory calculations that are similar to those in our earlier studies. [31-32] The first method uses the semi-empirical Troe formulation to rationalize the results while the second is a full RRKM calculation. [33] Both formulations are single channel type calculations and therefore disregard the effects of population depletion by the lower energy channel on the dissociation rate for the higher energy channel. The third method is also a full RRKM calculation (Program UNIMOL from Gilbert et al. [34]); however, it utilizes a full weak' collision Master's equation analysis for the energy transfer processes. Here the mutual interferences of population effects for both channels are included in order to determine the total rate of depletion and the branching fractions into the product channels.

The models used and the results from the respective calculations are given in Table 3. All three methods conclude that the threshold energy for C-I fission is $(52.0 \pm 0.5)$ with molecular elimination being lower by $\sim 3 \mathrm{kcal}$ mole-1. This suggests $\Delta_{f} H_{0 K\left(C_{2} H_{5} l\right)}^{0}=$ $5.0 \mathrm{kcal} \mathrm{mole}^{-1}$; i. e., $2.8 \mathrm{kcal} \mathrm{mole}^{-1}$ higher than the Carson et al. [8] value. This new value and $E_{0(2)}=48.9 \mathrm{kcal}_{\text {mole }}{ }^{-1}$ suggests a potential energy barrier of $32.5 \mathrm{kcal} \mathrm{mole}^{-1}$ for $\mathrm{HI}$ insertion into $\mathrm{C}_{2} \mathrm{H}_{4}$.

Excluding Lennard-Jones $\mathrm{Kr}-\mathrm{C}_{2} \mathrm{H}_{5} \mathrm{I}$ collision parameters (calculated by methods outlined by Cambi et al. [37], implying $\sigma_{12}=4.071 \AA$ and $\varepsilon_{12}=284.3 \mathrm{~K}$ ), the first two models in Table 3 involve adjusting 4 parameters, $E_{0(1)}, E_{0(2)},\left\langle\Delta E_{1}\right\rangle_{d o w n}$, and $\left\langle\Delta E_{2}\right\rangle_{d o w n}$ in order to give good agreement for both the pressure dependent rate constants and the experimental yield, 0.87. A T-independent yield could be conserved (Fig. 1) if $\left\langle\Delta E_{2}\right\rangle_{\text {down }}$ was substantially less than $\left\langle\Delta E_{1}\right\rangle_{\text {down }}$ (see Table 3). However, the UNIMOL formulation successfully agreed with the data using a common energy transfer parameter, $410 \mathrm{~cm}^{-1}$. The calculated values for the yields do however show a slight $\mathrm{T}$-dependence as seen by the dashed line in Fig. 1. Clearly this slight variation is well within the data scatter. In all three 
calculations, the predictions show unambiguously that both reactions (1) and (2) are strongly affected by pressure fall-off. This is undoubtedly due to the large number of degrees of freedom and, in particular, the values for the low lying frequencies in $\mathrm{C}_{2} \mathrm{H}_{5} \mathrm{I}$. This justifies presenting the data as first-order in Fig. 4.

A comparison between the predicted density dependences from the UNIMOL calculation and experiment is shown in Fig. 5 where the present data in Table 2 have been plotted as second-order. The quality of fits with the first two methods is similar to that shown with this third method. Extrapolation of the third model to the conditions of Mertens et al. [5] predicts rate constants that are in excellent agreement with experiment. Lastly, our calculations show that the low temperature data of Yang and Conway [15] are not near the high pressure limit for reaction (2) as they had presupposed. Hence, ambiguities exist as to what collisional energy transfer parameter to use when toluene is the third body. With a high $\beta_{c}$, we predict a yield of $\sim 0.8$ to be compared to their rough estimate of 0.7 , and the predicted apparent activation energy is $\sim 51$ whereas they report $52.8 \mathrm{kcal} \mathrm{mole}-1$.

Even though the single channel models can probably be used to assess the threshold energies for the two processes, rationalization of the data requires substantially different values for the two $\langle\Delta E\rangle_{\text {down }}$ values. We agree with Just [1] that weak collisional energy transfer for multi-channel dissociations should be considered with a unified model. In this instance, Master's equation analysis (Program UNIMOL) is clearly appropriate, and, as noted earlier, its application requires one less parameter to rationalize the data.

\section{Acknowledgments}

We thank B. Kirtman for providing us with a vibrational analysis for the HI elimination transition state. This work was supported by the U. S. Department of Energy, Office of Basic Energy Sciences, Division of Chemical Sciences, under Contract No.W31-109-Eng-38. 


\section{References}

1 Just, Th., Twenty-Fifth Symposium (International) on Combustion, The Combustion Institute, Pittsburgh, 1994, pp. 687-703.

2 Lim, K. P., and Michael, J. V., Twenty-Fifth Symposium (International) on Combustion, The Combustion Institute, Pittsburgh, 1994, pp. 809-816.

3 Lim, K. P., and Michael, J. V., J. Phys. Chem. 98: 211-215 (1994).

4 Herzler, J., and Frank, P., Ber. Bunsenges. Phys. Chem. 96: 1333-1338 (1992).

5 Mertens, J. D., Wooldridge, M. S., and Hanson, R. K., Eastern States Section 1994 Technical Meeting, The Combustion Institute, Pittsburgh, PA, paper presentation.

6 Toto, J. L., Pritchard, G. O., and Kirtman, B., J. Phys. Chem. 98: 8359-8370 (1994).

7 Wolfe, S., and Kim, C. K., Israel J. Chem. 33: 295-305 (1993).

8 Carson, A. S., Laye, P. G., Pedley, J. B., Welsby, A. M., Chickos, J. S., and Hosseini, S., J. Chem. Thermodynamics 26: 1103-1109 (1994).

9 Chase, M. W., Jr., Davies, C. A., Downey, J. R., Jr., Frurip, D. J., McDonald, R. A., and Syverud, A. N., J. Phys. Chem. Ref. Data 14: Supplement No. 1 (1985).

10 Hanning-Lee, M. A., Green, N. J. B., Pilling, M. J., and Robertson, S. H., J. Phys. Chem. 97: 860-870 (1993).

11 Benson, S. W., and O'Neal, H. E., Kinetic Data on Gas Phase Unimolecular Reactions, National Stand. Ref. Data Ser., U.S., Nat'l. Bur. Stand., Washington, D. C., 1970.

12 Ogg, R. A., Jr., J. Am. Chem. Soc. 56: 526-536 (1934).

13 Sullivan, J. H., J. Phys. Chem. 65: $722-727$ (1961).

14 Butler, E. T., and Polanyi, M., Trans. Faraday Soc. 39: 19-36 (1943).

15 Yang, J.-H., and Conway, D. C., J. Chem. Phys. 43: 1296-1303 (1965).

16 Michael, J. V., Prog. Energy Combust. Sci. 18: 327-347 (1992). 
17 Michael, J. V., in Advances in Chemical Kinetics and Dynamics (J. R. Barker, Ed.), JAI, Greenwich, 1992, Vol. 1, p. 47, for original references.

18 Michael, J. V., and Sutherland, J. W., Int. J. Chem. Kinet. 18: 409-436 (1986).

19 Michael, J. V., J. Chem. Phys. 90: 189-197 (1989).

20 Michael, J. V., and Fisher, J. R., in Seventeenth International Symposium on Shock Waves and Shock Tubes, AIP Conference Proceedings 208 (Y. W. Kim, Ed.), American Institute of Physics, New York, 1990, p. 210.

21 Lim, K. P., and Michael, J. V., Twenty-Fifth Symposium (International) on Combustion, The Combustion Institute, Pittsburgh, 1994, pp. 713-719, and references cited therein.

22 Lynch, K. P., Schwab, T. C., and Michael, J. V., Int. J. Chem. Kinet. 8: 651-671 (1976).

23 Maki, R. G., Michael, J. V., and Sutherland, J. W., J. Phys. Chem. 89: 4815-4821 (1985).

24 Kumaran, S. S., Lim, K. P., and Michael, J. V., J. Chem. Phys. 101: 9487-9498 (1994).

25 Kumaran, S. S., Su, M.-C., Lim, K. P., and Michael, J. V., Chem. Phys. Lett. 243: 59-63 (1995).

26 Radzig, A. A., and Smirnov, B. M., Reference Data on Atoms, Molecules, and Ions, Springer Ser. Chem. Phys., Springer-Verlag, Heidelberg, 1985, Vol. 39.

27 Takahashi, A., Inoue, A., and Inomata, T., Twentieth International Symposium on Shock Waves, Pasadena, CA, 1995, paper presentation.

28 Braun-Unkoff, M., Frank, P., and Just, Th., Ber. Bunsenges. Phys. Chem. 94: 14171425 (1990).

29 Baulch, D. L., Duxbury, J., Grant, S. J., and Montague,.D. C., J. Phys. Chem. Ref. Data 10: Supplement No. 1, 1-1 (1981). 
30 Westley, F., Frizzel, D. H., Herron, J. T., Hampson, R. F., and Mallard, W. G., NIST Chemical Kinetics Database - ver. 5.0, NIST Standard Reference Database 17, Gaithersburg, MD (1993).

31 Kumaran, S. S., Lim, K. P., Michael, J. V., and Wagner, A. F., J. Phys. Chem. 99: 8673-8680 (1995).

32 Kumaran, S. S., Su, M.-C., Lim, K. P., Michael, J. V., and Wagner, A. F., J. Phys. Chem., in press.

33 Troe, J., J. Chem. Phys. 66: 4745-4757 (1977); ibid. 66: 4758-4775 (1977); Troe, J., J. Phys. Chem. 83: 114-??? (1979); Troe, J., Ber. Bunsenges. Phys. Chem. 87: 161169 (1983); Gilbert, R. G., Luther, K., and Troe, J., Ber. Bunsenges. Phys. Chem. 87: 169-177 (1983).

34 Gilbert, R. G., Simth, S. C., and Jordan, M. J. T., Program package UNIMOL program suite (1993), School of Chemistry, Sydney University, NSW 2006, Australia, Gilbert_R@summer.chem.su.oz.au.

34 Herzberg, G., Electronic Spectra of Polyatomic Molecules, Van Nostrand, Princeton, 1966, p. 647.

36 Feng, Y., Niiranen, J. T., Bencsura, A., Knyazev, V. D., Gutman, D., and Tsang, W., J. Phys. Chem. 97: 871-880 (1993).

37 Cambi, R., Cappelletti, D., Liuti, G., and Pirani, F., J. Chem. Phys. 95: 1852-1861 (1991). 
Table 1: $\quad$ Mechanism for $\mathrm{C}_{2} \mathrm{H}_{5} \mathrm{I}$ Pyrolysis.

1. $\mathrm{C}_{2} \mathrm{H}_{5} \mathrm{I}+\mathrm{M} \rightarrow \mathrm{C}_{2} \mathrm{H}_{5}+\mathrm{I}+\mathrm{M} \quad \mathrm{k}_{1}=$ to be fitted

1a. $\mathrm{C}_{2} \mathrm{H}_{5} \rightarrow \mathrm{C}_{2} \mathrm{H}_{4}+\mathrm{H}$

$\mathrm{k}_{1 \mathrm{a}}=\infty$

2. $\mathrm{C}_{2} \mathrm{H}_{5} \mathrm{I}+\mathrm{M} \rightarrow \mathrm{C}_{2} \mathrm{H}_{4}+\mathrm{HI}+\mathrm{M}$

$\mathrm{k}_{2}=$ to be fitted

3. $\mathrm{H}+\mathrm{HI} \rightarrow \mathrm{H}_{2}+\mathrm{I}$

$\mathrm{k}_{3}=7.87 \times 10^{-11} \exp (-330 \mathrm{~K} / \mathrm{T})^{\mathrm{a}}$

aRef. 29 , units are $\mathrm{cm}^{3}$ molecule $\mathrm{e}^{-1} \mathrm{~s}^{-1}$. 
Table 2: Kinetics Data for the Thermal Dissociation of $\mathrm{C}_{2} \mathrm{H}_{5} \mathrm{I}$.

\begin{tabular}{|c|c|c|}
\hline $\mathrm{P}_{1} /$ (Torr) & ${ }^{\mathrm{a}} \mathrm{M}_{\mathrm{s}}{ }^{\mathrm{b}} \rho_{5} /\left(10^{18} \mathrm{~cm}^{-3}\right) \mathrm{k}_{1 \mathrm{st}} /\left(\mathrm{s}^{-1}\right)$ & ${ }^{\mathrm{b}} \mathrm{T}_{5} /(\mathrm{K}) \mathrm{ck}_{1} /\left(\mathrm{cm}^{3}\right.$ molecule $\left.^{-1} \mathrm{~s}^{-1}\right)$ \\
\hline
\end{tabular}

H-atom Results:

$$
\mathrm{X}_{\mathrm{C}_{2} \mathrm{H}_{5} \mathrm{I}}=6.273 \times 10^{-7}
$$

8.41

2.197

1.410

9500

1230

$6.74 \times 10^{-15}$

$\mathrm{X}_{\mathrm{C}_{2} \mathrm{H}_{5} \mathrm{I}}=2.087 \times 10^{-7}$

$\begin{array}{rrrrrr}15.91 & \cdot 2.054 & 2.464 & 1800 & 1100 & 7.30 \times 10^{-16} \\ 15.89 & 2.029 & 2.416 & 1350 & 1080 & 5.59 \times 10^{-16} \\ 15.86 & 2.177 & 2.633 & 12000 & 1217 & 4.56 \times 10^{-15}\end{array}$

I-atom Results:

$\begin{array}{rrr}\mathrm{X}_{\mathrm{C}_{2} \mathrm{H}_{5} \mathrm{I}=} & & \\ & & \\ 275 & 946 & 1.82 \times 10^{-16} \\ 7443 & 1161 & 4.22 \times 10^{-15} \\ 2665 & 1106 & 1.27 \times 10^{-15} \\ 2290 & 1117 & 9.12 \times 10^{-16} \\ 5300 & 1118 & 1.70 \times 10^{-15} \\ 650 & 1000 & 1.48 \times 10^{-16} \\ 9500 & 1150 & 5.43 \times 10^{-15} \\ 825 & 1019 & 5.17 \times 10^{-16} \\ 3200 & 1101 & 1.29 \times 10^{-15}\end{array}$

$\mathrm{X}_{2} \mathrm{H}_{5} \mathrm{I}=9.976 \times 10^{-7}$

$\begin{array}{rrrrrr}10.63 & 2.053 & 1.637 & 3800 & 1089 & 2.32 \times 10^{-15} \\ 10.96 & 1.957 & 1.583 & 1300 & 1000 & 8.21 \times 10^{-16} \\ 10.96 & 2.223 & 1.864 & 17000 & 1256 & 9.12 \times 10^{-15} \\ 10.97 & 2.055 & 1.692 & 3900 & 1091 & 2.30 \times 10^{-15}\end{array}$

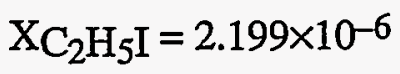

$\begin{array}{rrrrrr}5.97 & 2.195 & 0.996 & 18000 & 1232 & 1.81 \times 10^{-14} \\ 5.97 & 2.080 & 0.936 & 9000 & 1115 & 9.62 \times 10^{-15} \\ 5.95 & 2.244 & 1.023 & 26240 & 1278 & 2.56 \times 10^{-14} \\ 5.94 & 2.155 & 0.973 & 7500 & 1188 & 7.71 \times 10^{-15} \\ 5.96 & 2.135 & 0.965 & 9000 & 1168 & 9.32 \times 10^{-15}\end{array}$


Table 2 (cont.)

\begin{tabular}{llrrrl}
\hline $\mathrm{P}_{1} /(\mathrm{Torr})$ & $\mathrm{a}_{\mathrm{M}}$ & $\mathrm{b}_{\rho_{5} /\left(10^{18} \mathrm{~cm}^{-3}\right)} \mathrm{k}_{1 \mathrm{st}} /\left(\mathrm{s}^{-1}\right)$ & $\mathrm{b}_{5} /(\mathrm{K})$ & $\mathrm{ck}_{1} /\left(\mathrm{cm}^{3} \mathrm{molecule}^{-1} \mathrm{~s}^{-1}\right)$ \\
& & & & & \\
\hline 5.94 & 2.268 & 1.034 & 27000 & 1303 & $2.61 \times 10^{-14}$ \\
5.95 & 2.043 & 0.911 & 3400 & 1080 & $3.73 \times 10^{-15}$ \\
5.96 & 1.899 & 0.825 & 220 & 948 & $2.67 \times 10^{-16}$ \\
5.88 & 1.976 & 0.858 & 2100 & 1021 & $2.45 \times 10^{-15}$ \\
& & & & & \\
& & & $\mathrm{X}_{2} \mathrm{H}_{5} \mathrm{I}=9.976 \times 10^{-7}$ & \\
15.91 & 2.168 & 2.638 & 13250 & 1204 & $5.02 \times 10^{-15}$ \\
15.91 & 2.067 & 2.492 & 4950 & 1108 & $1.99 \times 10^{-15}$ \\
15.90 & 1.889 & 2.212 & 250 & 948 & $1.13 \times 10^{-16}$ \\
15.95 & 1.959 & 2.324 & 1000 & 1013 & $4.30 \times 10^{-16}$ \\
15.94 & 2.003 & 2.400 & 1800 & 1049 & $7.50 \times 10^{-16}$ \\
15.99 & 2.041 & 2.457 & 3090 & 1087 & $1.26 \times 10^{-15}$ \\
15.99 & 2.034 & 2.455 & 2825 & 1077 & $1.15 \times 10^{-15}$ \\
15.86 & 2.112 & 2.541 & 7822 & 1154 & $3.08 \times 10^{-15}$ \\
15.90 & 2.171 & 2.632 & 13300 & 1212 & $5.05 \times 10^{-15}$ \\
15.87 & 1.970 & 2.331 & 1290 & 1023 & $5.53 \times 10^{-16}$ \\
& & & & & \\
\hline
\end{tabular}

aThe error in measuring the Mach number, $\mathrm{M}_{\mathrm{S}}$, is typically $0.5-1.0 \%$ at the one standard deviation level. bQuantities with subscript 5 refer to the thermodynamic state of the gas in the reflected shock region. "The rate constants are derived as described in the text. 
Table 3: Theoretical Calculations for the Dissociation Reaction: $\mathrm{C}_{2} \mathrm{H}_{5} \mathrm{I}(+\mathrm{M}) \rightarrow$ Prods.

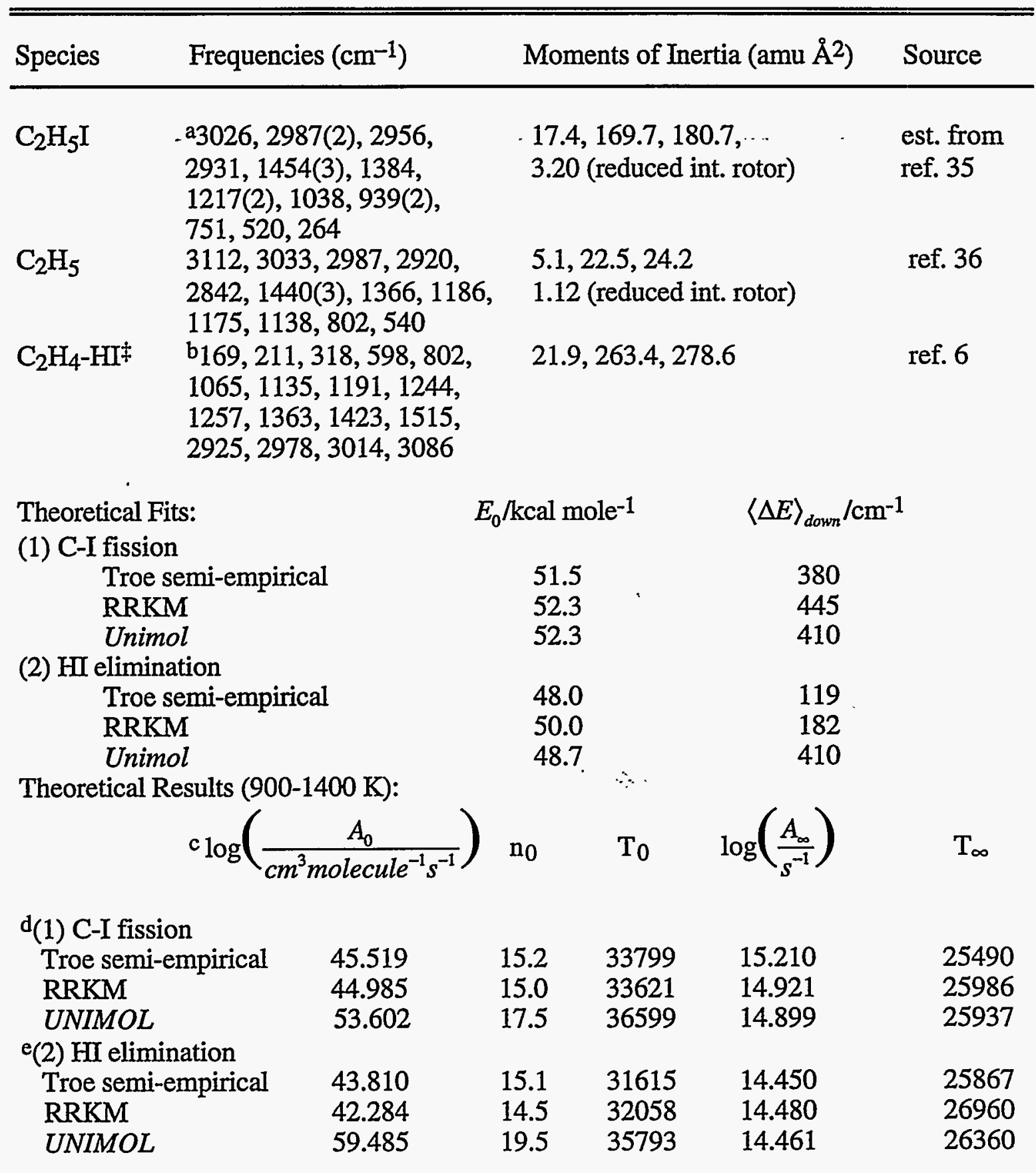

aThese frequencies are in good agreement with our scaled STO-3G RHF-SCF $a b$ initio calculations. bThese frequencies are from B. Kirtman and are based on Gaussian $94 a b$ initio calculations presented in ref. 6 . In accordance with usual practice, they are scaled by 0.9. $\mathrm{ck}_{\mathrm{i}}=\mathrm{A}_{i} \mathrm{~T}^{-\mathrm{n}} \mathrm{exp}(-\mathrm{Ti} / \mathrm{T})$ three parameter fits for limiting low- and high-pressure rate constants. ${ }^{\mathrm{d}}$ The derived values of $k_{-1}^{\infty}$ for each of the models from top to bottom are: 7.7, 5.5 , and $(5.5 \pm 0.2) \times 10^{-11} \mathrm{~cm}^{3}$ molecule-1 $\mathrm{s}^{-1}$. eThe derived values of $k_{-2}^{\infty}$ for each of the models from top to bottom are: $2.78 \times 10^{-11} \exp (-18219 \mathrm{~K} / \mathrm{T}), 2.79 \times 10^{-11}$ $\exp (-18978 \mathrm{~K} / \mathrm{T})$, and $3.11 \times 10^{-11} \exp (-18533 \mathrm{~K} / \mathrm{T}) \mathrm{cm}^{3}$ molecule $\mathrm{e}^{-1} \mathrm{~s}^{-1}$. 


\section{Figure Captions}

Figure 1: Plot of yield data, $-\mathrm{H}$-atoms and $\mathrm{O}-\mathrm{I}$-atoms, for reaction (1) against $\mathrm{T}^{-1}$ for $948 \leq T \leq 2046 \mathrm{~K}$. The combined sets give the yield $=0.87$ (solid line). The dashed line is the UNIMOL prediction (see text).

Figure 2: The top panel shows a typical experimental H-atom ARAS signal, and the bottom panel shows the corresponding $[\mathrm{H}]_{\mathrm{t}}$ obtained from line absorption calculations (see text). The conditions are: $\left[\mathrm{C}_{2} \mathrm{H}_{5}\right]_{0}=8.84 \times 10^{11} \mathrm{~cm}^{-3}$ at $\mathrm{T}$ $=1230 \mathrm{~K}$ and $\rho=1.410 \times 10^{18} \mathrm{~cm}^{-3}$. The solid line is the calculated fit using the mechanism of Table 1 with $[\mathrm{H}]_{\infty}=0.71\left[\mathrm{C}_{2} \mathrm{H}_{5} \mathrm{I}_{0}\right.$ and $\mathrm{k}_{1}=9500 \mathrm{~s}^{-1}$.

Figure 3: The top panel shows a typical experimental I-atom ARAS signal, and the bottom panel shows the corresponding $[\mathrm{I}]_{\mathrm{t}}$ obtained using eqn. (3). The conditions are: $\left[\mathrm{C}_{2} \mathrm{H}_{5}\right]_{0}=2.62 \times 10^{12} \mathrm{~cm}^{-3}$ at $\mathrm{T}=1106 \mathrm{~K}$ and $\rho=2.105 \mathrm{x}$ $10^{18} \mathrm{~cm}^{-3}$. The solid line is the calculated fit using the mechanism of Table 1 with []$_{\infty}=0.83\left[\mathrm{C}_{2} \mathrm{H}_{5} \Pi\right]_{0}$ and $\mathrm{k}_{1}=2665 \mathrm{~s}^{-1}$.

Figure 4: Arrhenius plot of measured first-order rate constants for reaction (1), using $\mathrm{H}-$ and I-atom ARAS techniques. The solid line represents a linear-leastsquares fit given by eqn. (4).

Figure 5: Arrhenius plots of measured second-order rate constants for reaction (1)

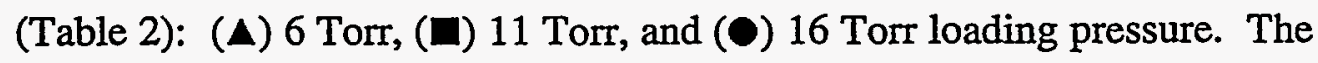
solid lines are UNIMOL predictions using the Table 3 model (see text). 


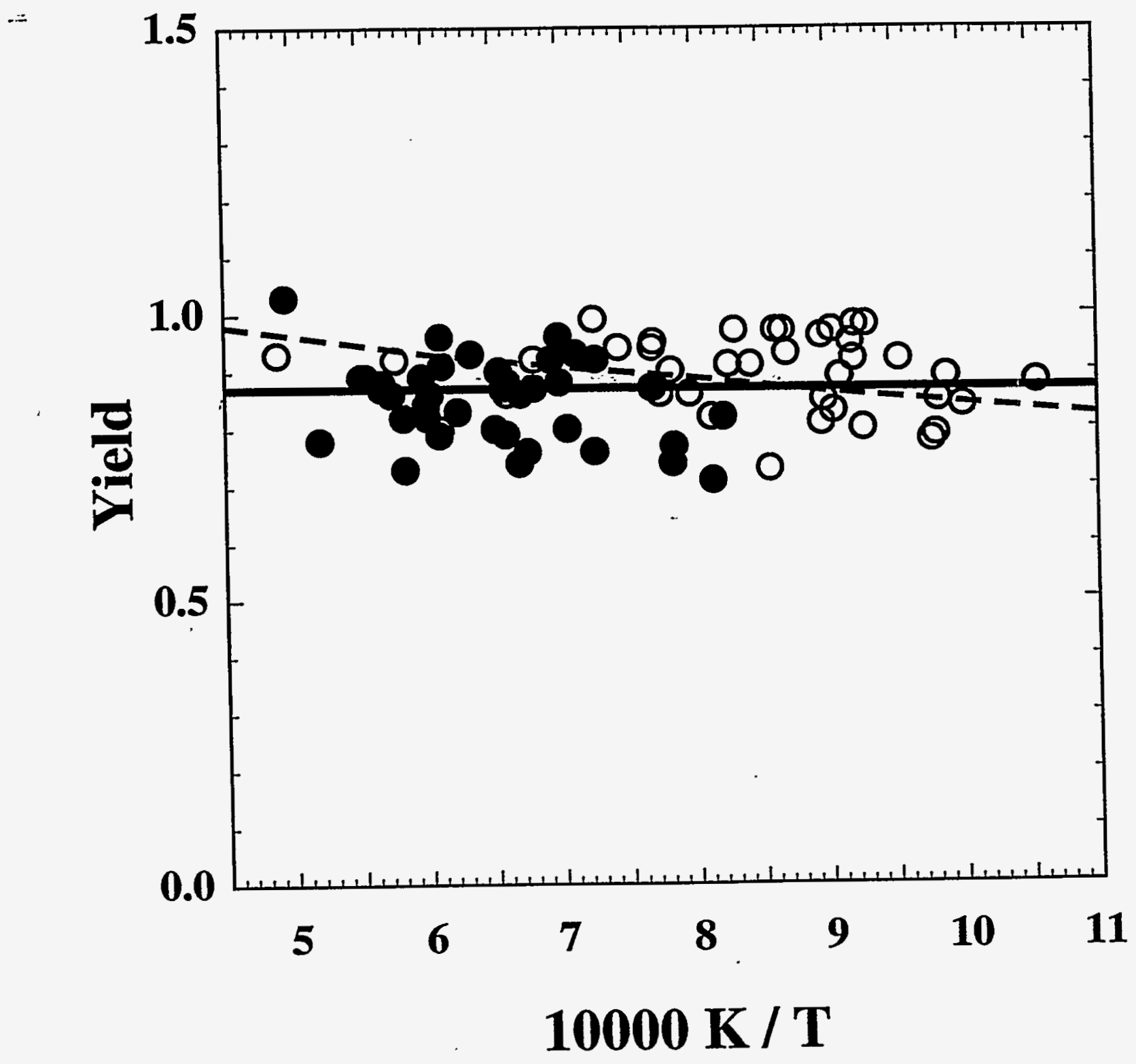

Figure 1 

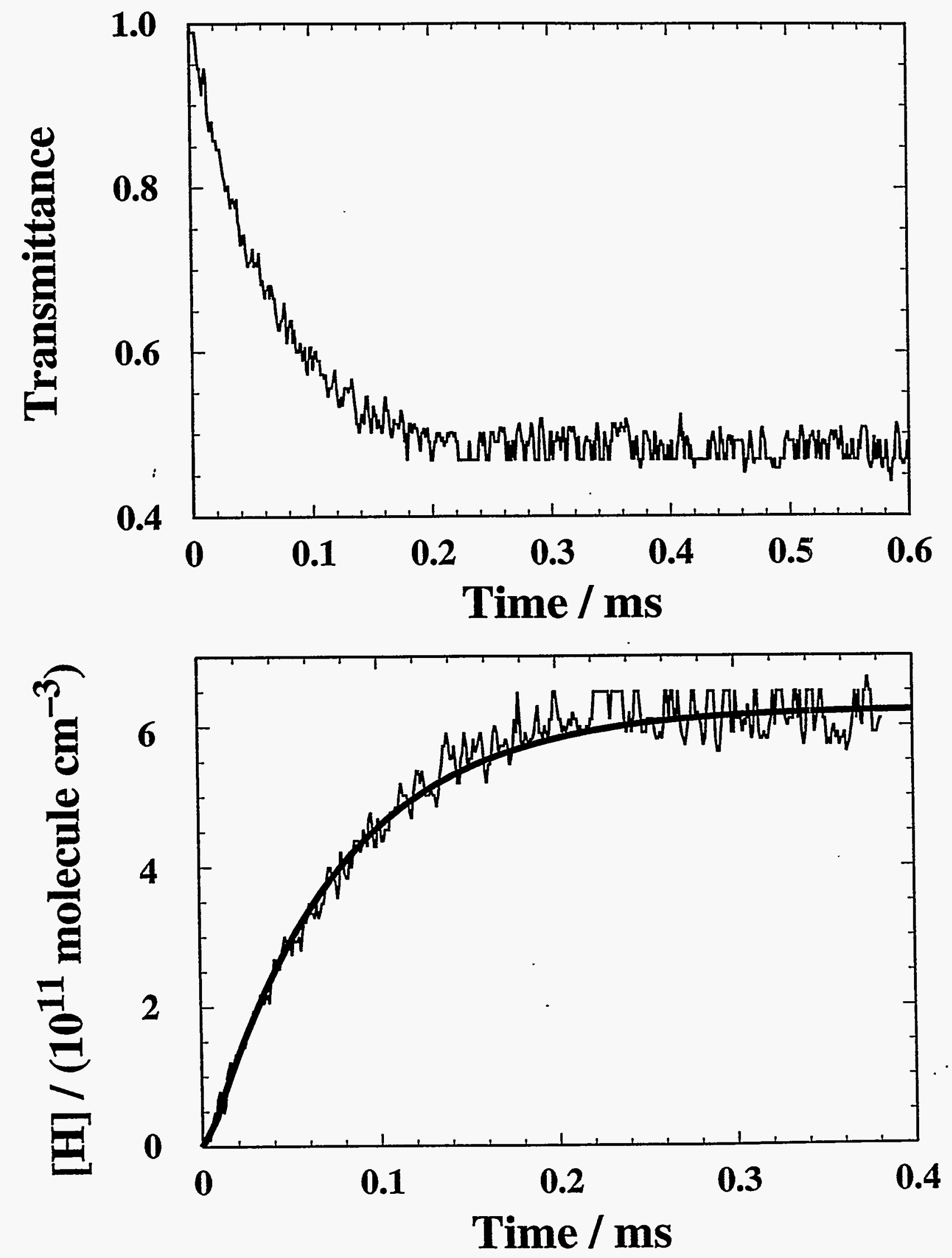

Figure 2 

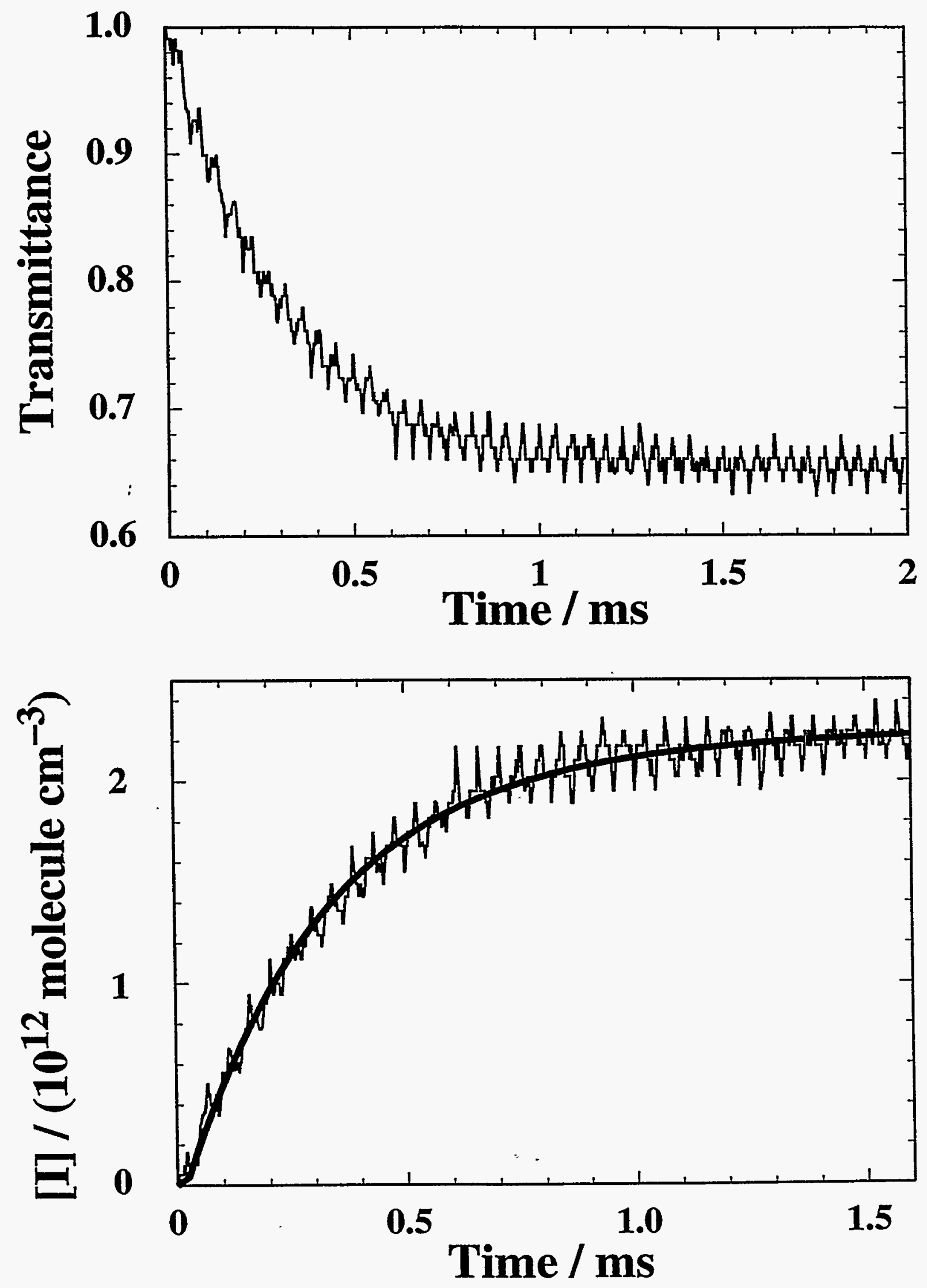

Figure 3 


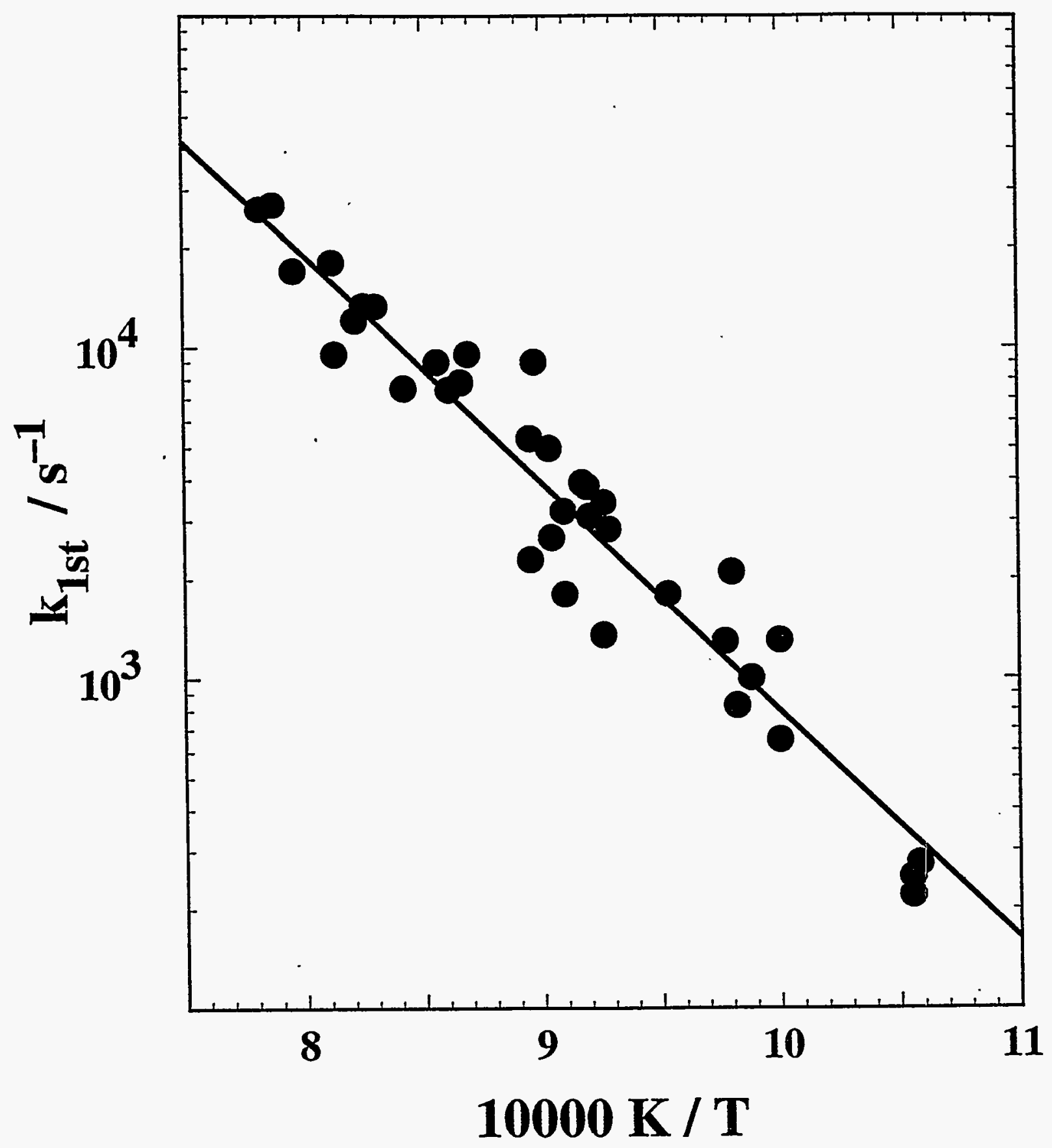

Figure 4 


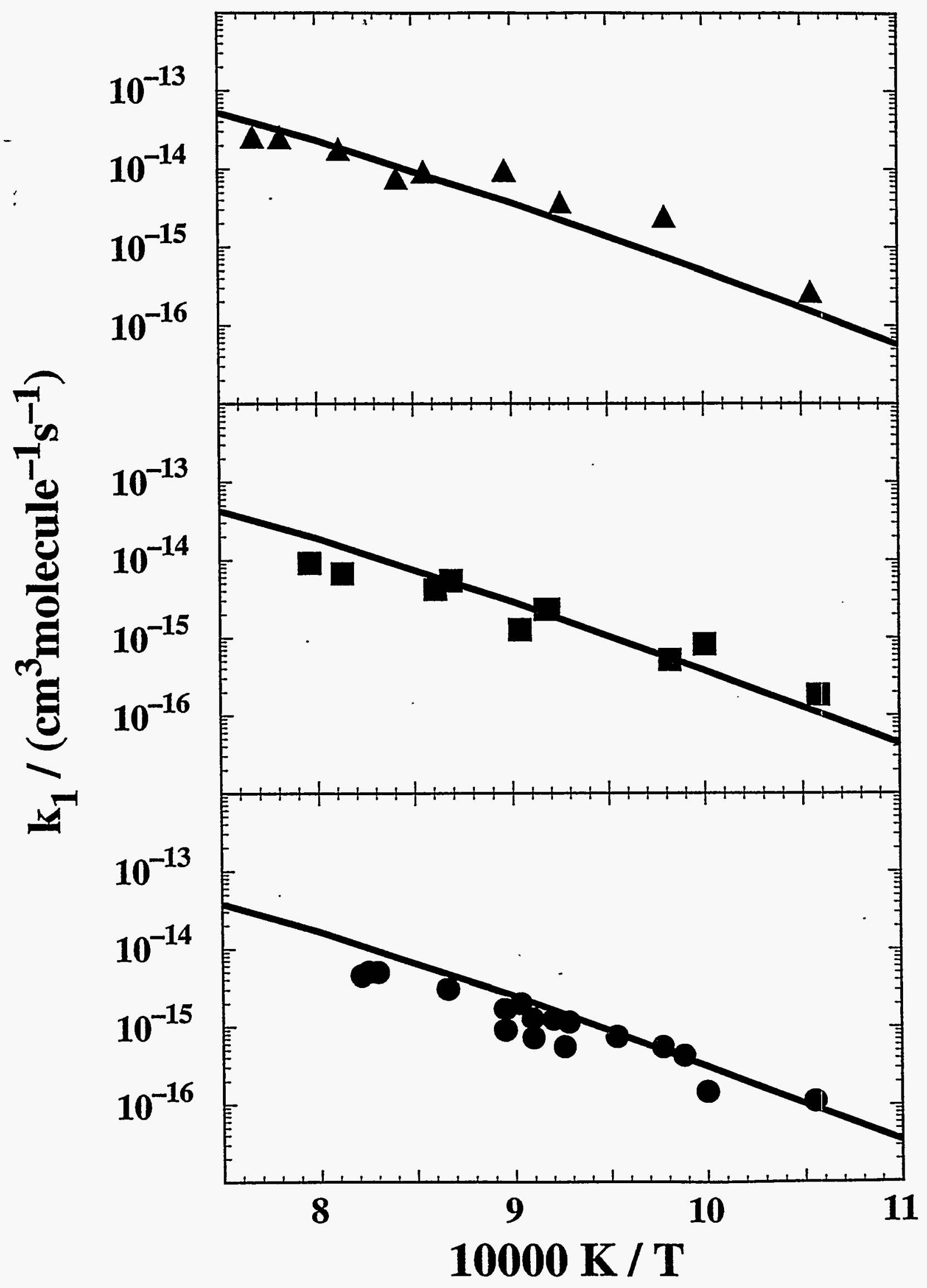

Figure 5 